\title{
THIAMINE STATUS OF HUMAN SUBJECTS, ESTIMATED BY BIOCHEMICAL METHODS
}

\author{
D. Hötzel and R. Bitsch \\ Institut für Ernährungswissenschaft der Universität Bonn, Germany
}

Specific clinical symptoms caused by thiamine deficiency do not occur in the population of industrialized countries living under normal conditions and practicing normal food habits without excessive alcohol consumption. Nevertheless it can not be excluded that those persons to some extent may be suboptimal supplied with thiamine because slight symptoms of deficiency are nonspecific and therefore usually will not be recognized as early signs of insufficient supply.

During the last decades food habits have changed in industrialized societies to some extent. With regard to thiamine the decreasing intake of food rich in thiamine and important for supply is remarkable. Food from whole grain, potatoes and legumes belong to that sort of food as well as internal organs for instance.

Because of the importance of the "thiamine problem" the thiamine intake of different groups of the population had been checked in most countries and regions. In Germany (BRD) for example the average thiamine intake had been calculated by food balance sheets to amount to $1.8 \mathrm{mg}$ per day (1). Twenty percent are to be substracted from $1.8 \mathrm{mg}$ for losses by destruction during storage and preparation of food $(1,2)$. Because the German Nutrition Society recommends for adults an intake of $1.5 \mathrm{mg}(2)$ the requirement seems to be met by the population in average. But in more detailed studies investigators demonstrated that individual values are widely dispersed around the mean thiamine intake, insofar leading to the conclusion that part of the collective ingest less thiamine than recommended.
Much more reliable than calculations about the thiamine status (thiamine intake compared to requirement) are determinations of reactions of the organism dependent on the amount of thiamine available. The erythrocyte transketolase (ETK) test (3) belongs to such type of methods (modifications by Dreyfus (4), Schouten (5), Massod (6) and others). More informations than ETK activity itself gives the $\alpha_{\text {EтK }}$ after stimulating the actual enzyme activity by addition of thiamine pyrophosphate (TPP) in vitro.

This paper deals with the application of the ETK method for examining the status of students. Students are rather a homogeneous group because they are living in simular situations, participate in "mensa" massfeeding and belong to the same age group. A main reason for examining students was the fact that they often maintain unusual food customs.

\section{EXPERIMENTAL}

One hundred and thirty students have been selected from 260 volunteers. The chosen subjects being in a good state of health did not use pharmaceuticals (except contraceptiva, see below). About $70 \%$ of them represented a group with normal body weight according to the BROCA-index. $12.5 \%$ exhibited overweight, approximately $10 \%$ showing underweight. $65 \%$ of them were females, $34 \%$ males, half of the females used contraceptiva. Smokers were distributed in equal ratio in the 3 groups. At the start of the experiment anthropometric characteristics were ascertained and blood and urine samples were taken in the early morning before breakfast. Food records were conducted in the preexperimental period 
and during the study. After collection of blood and urine the students received B-vitamins excepting pantothenic acid in a dosage twice the daily requirement for a period of 2 weeks. The students were advised to consume a diet rich in protein. At the end of the study the same procedure as in the beginning was carried through. ETK-measurement and $\alpha_{\text {ETK }}$ were performed according to the method of Dreyfus (4) modified by Schouten (5) and Vuilleumier (7). The statistical evaluation of the results had been accomplished according to the method of Student's $t$ test. The study was repeated in May 1975 in the same way but pantothenic acid administered twice the daily requirement too.

\section{RESULTS AND DISCUSSION}

The daily supplementation of $2 \mathrm{mg}$ thiamine for 2 weeks had the most striking effect on erythrocyte transketolase activity as well as $\alpha_{\text {ETK }}$ comparing to other variables. Table 1

Table 1. Differences and correlations: thiamine status of several groups of students.

\begin{tabular}{|c|c|c|c|c|}
\hline group & questions & $\begin{array}{c}\mathrm{ETK}(\mathrm{U} / \mathrm{l}) \\
\vec{x} \pm s\end{array}$ & $P$ & Correl. \\
\hline$\Sigma$ & $\begin{array}{l}+\mathrm{B}_{1}^{\mathrm{a}} \\
1 \text { vs. } 2^{\mathrm{b}}\end{array}$ & $\begin{array}{l}52.8 \pm 13.6 \\
60.7 \pm 13.4\end{array}$ & 0.001 & $0.15(+)$ \\
\hline Male & $\begin{array}{l}+\mathrm{B}_{1} \\
1 \text { vs. } 2\end{array}$ & $\begin{array}{l}49.8 \pm 10.6 \\
61.3 \pm 13.2\end{array}$ & 0.001 & $<0.3(+)$ \\
\hline Female & $\begin{array}{l}+\mathrm{B}_{1} \\
1 \text { vs. } 2\end{array}$ & $\begin{array}{l}54.5 \pm 13.8 \\
60.3 \pm 11.7\end{array}$ & 0.005 & $<0.3(+)$ \\
\hline$\Sigma(1)$ & $\begin{array}{l}\text { Female } \\
\text { vs. male }\end{array}$ & $\begin{array}{l}54.5 \pm 13.8 \\
49.8 \pm 10.6\end{array}$ & 0.050 & \\
\hline$\Sigma(1)$ & $\begin{array}{l}\text { ETK } v s . \\
\alpha_{\text {ETK }}\end{array}$ & $\begin{array}{c}52.8 \pm 13.6 \\
1.126 \pm 0.121\end{array}$ & & \\
\hline$\Sigma(2)$ & $\begin{array}{l}\text { ETK } v s . \\
\alpha_{\text {ETK }}^{\prime}\end{array}$ & $\begin{array}{c}60.7 \pm 13.4 \\
1.056 \pm 0.046\end{array}$ & & $-0.33(+)$ \\
\hline
\end{tabular}

${ }^{\mathrm{a}} \mathrm{B}_{1}$ administration: $2 \mathrm{mg}$ per day for 2 weeks.

b 1 , start; 2 , end of study.

shows that the additional supply with thiamine to the usual, free chosen diet enhanced the mean value of ETK activity from $52.8 \mathrm{U}$ up to $60.7 \mathrm{U}$. The increase of activity in the male group was more intense than in female. At the beginning of the study the women exhibited a higher enzyme activity compared to men with a difference just significant at the borderline of $P=0.05$. After thiamine supplementation for 2 weeks significant differences between the

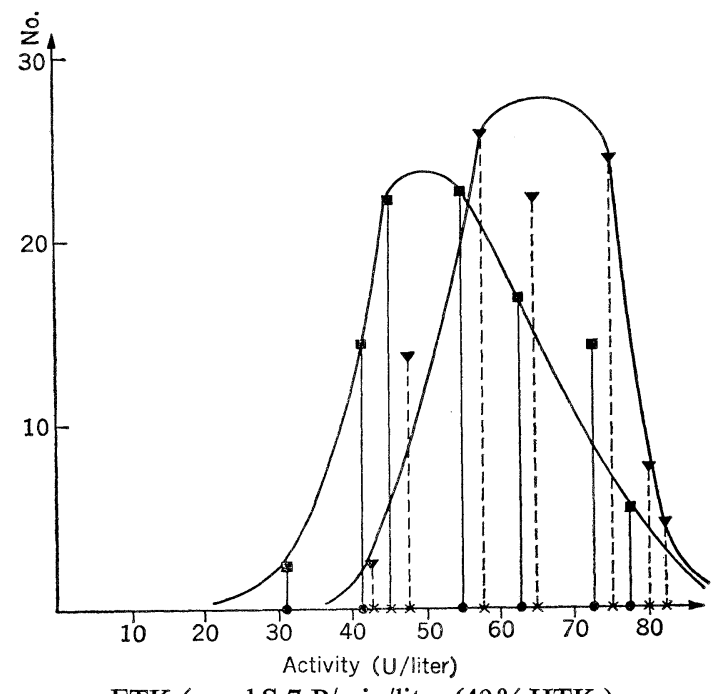

ETK ( $\mu \mathrm{mol} \mathrm{S-7-P/min/liter} \mathrm{(} 40 \%$ HTK.)

Fig. 1. ETK-activity of students. $2 \mathrm{mg} \mathrm{B}_{1} /$ day for 2 weeks (curves for tendency only).

$\mathbf{a}=$ before treatment with $\mathrm{B}_{1}(\max .83 .9 ; \min .3 .9)$

$\boldsymbol{\nabla}=$ after treatment with $B_{1}(\max .91 .0 ; \min .3 .3)$

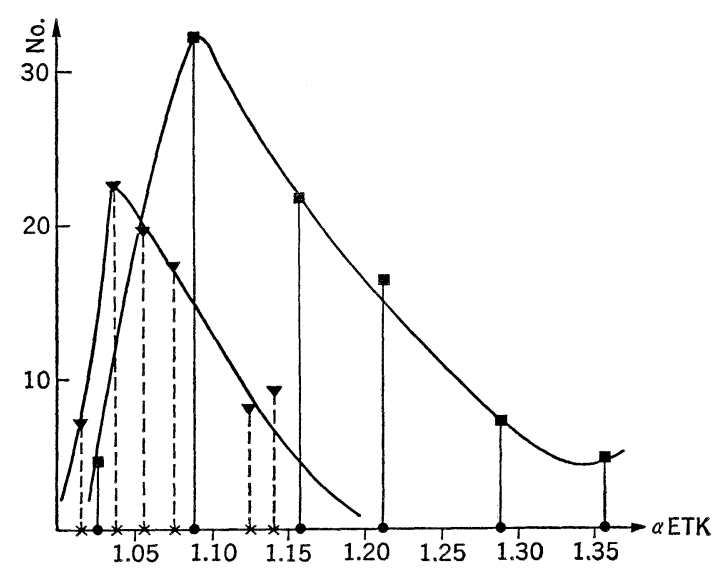

Fig. 2. $\alpha_{\text {ETK }}$ of students. Supplementation with thiamine, $2 \mathrm{mg} /$ day for 2 weeks (curves for tendency only).

$$
\begin{aligned}
& \boldsymbol{\nabla}=\text { before }(\max .1 .652) \\
& \boldsymbol{\nabla}=\text { after }(\max .1 .213)
\end{aligned}
$$

subgroups disappeared, as could be expected. ETK activity and $\alpha_{\text {ETK }}$ showed only a small, but significant negative correlation at start as well as at the end of the study, supporting the conclusion that in some respect enzyme activity or activation coefficient deliver informations supplementing each other. Similar observations were obtained by other investi- 
gators, too.

Figure 1 demonstrates the number of subjects distributing to the several values of ETK activity each before and after supplementation with thiamine. While the curves are overlapping, both peaks (before and after treatment with additional $\mathrm{B}_{1}$ ) are separated as in Fig. 2 with $\alpha_{\text {ETK }}$ as the criterion, too. Remarkably after supplementation, the maximum $\alpha_{\text {ETK }}$ of a single individuum amounted to 1.21. But generally the treatment of the subjects with thiamine decreased the ETK activation by TPP.

Table 2. Differences and correlations: thiamine status of several groups of students.

\begin{tabular}{|c|c|c|c|c|}
\hline Group & Question & $\begin{array}{l}\alpha_{\mathrm{ETK}} \\
\bar{x} \pm s\end{array}$ & $P$ & Correl. \\
\hline$\Sigma$ & $\begin{array}{l}+\mathrm{B}_{1}^{\mathrm{a}} \\
1 \text { vs. } 2^{\mathrm{b}}\end{array}$ & $\begin{array}{l}1.126 \pm 0.126 \\
1.056 \pm 0.046\end{array}$ & 0.001 & $\begin{array}{l}0.02 \\
\text { n.s. }\end{array}$ \\
\hline Male & $\begin{array}{c}+\mathbf{B}_{1} \\
1 \text { vs. } 2\end{array}$ & $\begin{array}{l}1.130 \pm 0.151 \\
1.054 \pm 0.051\end{array}$ & 0.010 & $\begin{array}{l}0.2 \\
\text { n.s. }\end{array}$ \\
\hline Female & $\begin{array}{l}+\mathrm{B}_{1} \\
1 \text { vs. } 2\end{array}$ & $\begin{array}{l}1.123 \pm 0.102 \\
1.057 \pm 0.043\end{array}$ & 0.001 & $\begin{array}{l}0.2 \\
\text { n.s. }\end{array}$ \\
\hline$\Sigma(1)$ & $\begin{array}{l}\text { Female } \\
\text { vs. male }\end{array}$ & $\begin{array}{l}1.123 \pm 0.102 \\
1.130 \pm 0.151\end{array}$ & n.s. & \\
\hline$\Sigma(1)$ & $\begin{array}{l}\text { Normal } \\
\text { u. weight }\end{array}$ & $\begin{array}{l}1.122 \pm 0.124 \\
1.082 \pm 0.056\end{array}$ & 0.05 & \\
\hline
\end{tabular}

\begin{tabular}{lrrrr}
\hline$\alpha_{\text {ETK }}$ & (1) & $77=69 \%$ & $23=20 \%$ & $12=10 \%$ \\
& & $<1.15$ & $>1.25$ \\
Distrib. (2) & $109=97 \%$ & $3=3 \%$ & $0=0 \%$ \\
\hline
\end{tabular}

a $B_{1}$ Administration: $2 \mathrm{mg}$ per day for 2 weeks.

b 1 , start; 2, end of study.

Table 2 summarizes the results with $\alpha_{\text {ЕTK }}$ as the criterion. It is to notice that the differences visible in ETK activity per se in most cases are to be seen also in the results based on $\alpha_{\text {ETK. }}$. But the difference between males and females is statistically significant with ETK as the criterion and not significant on the basis of $\alpha_{\text {ETK }}$ values. On the other hand subjects with underweight show significantly lower $\alpha_{\text {ETK }}$ values compared with normal body weight while ETK values are not different between these groups. It is to conclude that both parameters furnish partially different but supplemental informations.

At the beginning of our studies ETK estimates reflects the actual situation of thiamine status of the organism, dependent at thiamine intake during the preexperimental period. After thiamine supplementation in vivo exceeding the daily requirement the final capacity of the organism to produce the active enzyme had been measured in a condition in which thiamine can not be the limiting factor. The high standard deviations and the large differences between maximum and minimum values at this time reflect the big interindividual variations, which can not be related to thiamine. Therefore it has to be assumed, that after the refeeding period other factors than thiamine are responsible for the actual values of ETK activity and/or ETK is no more the rate limiting step for the activity of the pentose phosphate shunt.

The TPP addition to the test tube simulates the in vivo stimulation by thiamine but with the complete ETK coenzyme. By the TPP activation the maximal capacity of erythrocytes to produce the active enzyme is evaluated. It is to expect that identical absolute ETK values will be obtained whether after oral thiamine supply or by TPP addition in vitro. But application of the TPP activation exclude adaptive mechanisms, for example stimulation of the biosynthesis of the apoenzyme. Insofar the significant lower differences between groups can be expected if the TPP activation is applied, as far as the phosphorylation of thiamine does not become rate limiting. Actually, the increase of ETK activity by in vivo stimulation in percent $(x=15 \%)$ is larger than the $\alpha_{\text {ETK }}$ per se. Anyhow, the in vivo stimulation by additional thiamine should be always applied in this type of investigation.

Concerning the status of thiamine supply we obtained the following results when we applied the borders of Brin (8) for judging: On a free chosen diet as usually consumed by students the thiamine intake of most of our subjects was within the range of recommendations: The $\alpha_{\text {EтK }}$ of $69 \%$ of them was found to be less than 1.15. Twenty percent of the volunteers showed an $\alpha_{\text {ETK }}$ between 1.15 to 1.25 , and in $10 \%$ the activation of transketolasis by thiamine pyrophosphate in vitro 
amounted to more than 1.25 with a maximum $\alpha_{\mathrm{ETK}}$-value of 1.65 , pointing to a promoted status of thiamine undernutrition of a single person. After additional thiamine supply in vivo $97 \%$ of the subjects returned to sufficient $\alpha_{\mathrm{ETK}}$ values. In the one student with the formerly high ETK stimulation, a value close to 1.00 was observed, demonstrating his complete rehabilitation by in total $28 \mathrm{mg}$ thiamine. At that time his absolute ETK values was also in a normal range.

By a theoretical standpoint $\alpha_{\text {ETK }}$ can be expected to turn close to 1.00 after a refeeding period. Actually this did not happen in our studies. Also other investigators reported this phenomenon partially with seasonal differences (Brubacher (9), Ritzel (10), Buzina (11)). Somogyi (12) administered for in vivo stimulation of ETK very high amounts to thiamine (up to $50 \mathrm{mg}$ daily for 2 weeks). But in this case the subjects were alcoholics. An increase of the dosage to so much as $100 \mathrm{mg}$ daily was needed to reduce the activation effect of TPP in vitro to a really small amount. In our animal studies with doses $50 \%$ above the requirement we always obtained $\alpha_{\mathrm{ETR}}$ values in the range of 1.00 , in opposite to our results in

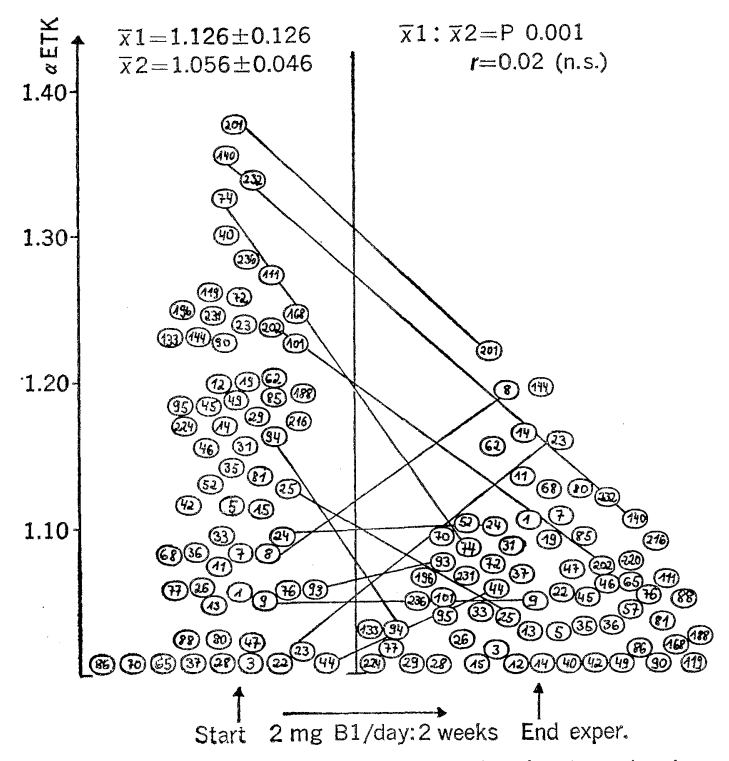

Fig. 3. $\alpha_{\text {ErK }}$ of students. Randomized selection from the whole collective. humans (unpublished results).

The influence of additional alimentary thiamine on $\alpha_{\text {ЕтK }}$ becomes amazing if not mean values but a distinct individual is observed. In Fig. 3 the values are reported for the time of starting the experiment and after the refeeding period, each for the same individuum. The registration number of each subject is noticed in circles. The figure contains only part of all values in order to facilitate orientation. A line connecting the first and the second value of the same person shows big individual differences. In some cases the $\alpha_{\mathrm{ETK}}$ values increase in other subjects they decline, or they remain unchanged. The general tendency can be demonstrated by two examples: $\alpha_{\text {Етк }}$ values on a higher level are reduced by thiamine administration in vivo as for example subject No. 201 shows. Representative for another tendency is subject No. 8: His $\alpha_{\mathrm{ETK}}$ value is increasing.

On the basis of our results it is to state, that some discrepancies are to be recognized in studies with humans using ETK activities and their stimulation, as Fig. 3 demonstrates. This observation leads to the conclusion, that more precise information about thiamine requirement will not be available if one applies the usual method of ETK activity and TPP stimulation.

Secondly it seems without practical importance to discuss $\alpha_{\text {ETK }}$ values in the border between 1.00 and 1.20 , if estimations of the status of thiamine supply are concerned.

\section{REFERENCES}

1) Deutsche Gesellschaft für Ernährung, Ernährungsbericht. 1972, Umschau-Verlag, Frankfurt.

2) Deutsche Gesellschaft für Ernährung, Empfehlungen für die Nährstoffzufuhr, Umschau-Verlag, Frankfurt (1975).

3) Brin, M., J. Am. Med. Ass., 187, 762 (1964).

4) Dreyfus, P.M., New Engl. J. Med., 267, 596(1962).

5) Shouten, H., van EPS Statius, L. W., and Boudier Struyker, A. M., Clin. Chim. Acta, 10, 474 (1974).

6) Massod, M. F., McGuire, S. L., and Werner, K. R., Amer. J. Clin. Pathol., 55, 465 (1971).

7) Vuilleumier, J.P., personal information from Hoffmann-La Roche AG, Basel. 
8) Brin, M., in G. u. W. Wolsterholm and M. O. Connor (Editors), Thiamine Deficiency, Ciba Foundation Group No. 28, J. A. Churchill, Ltd., London (1967).

9) Brubacher, G., Haenel, A., and Ritzel, G., Int. Z. Vitamin-Ernährungsforsch., 42, 451 (1972).

10) Ritzel, G., Int. Z. Vitamin-Ernährungsforsch., 38, 508 (1968).
11) Buzina, R., Jusic, M., Brodarec, A., Milanovic, N., Brubacher, G., Vuilleumier, J. P., Wiss, O., and Christeller, S., Int. Z. Vitamin-Ernährungsforsch., 41, 290 (1971).

12) Somogyi, J. C. and Kopp, P., in Proc. 9th Int. Congr. Nutrition, Mexico 1972, S. Karger, BaselMünchen-Paris-London-New York-Sydney, Vol.1, p. 212 (1975). 